\title{
Biopolimer Peptide Batteries-A New Concept for Environmentally Friendly and Safer Energy Storage
}

\author{
Volodymyr Moklyak $^{1}$, Andrii Hrubiak ${ }^{1, *} \mathbb{C}$, Zurab Gogitidze $^{2}$ and Yurii Yavorskyi ${ }^{3}$ \\ 1 G. V. Kurdyumov Institute for Metal Physics, N.A.S. of Ukraine, 36 Academician Vernadsky Boulevard, \\ 03142 Kyiv, Ukraine; mvvmcv@gmail.com \\ 2 Medical Information Center "Regul Medical”, 9 Starokyivska St., Apt 38., 03150 Kyiv, Ukraine; \\ 19zaza64@ukr.net \\ 3 Department of Physical Materials Science and Heat Treatment, National Technical University of Ukraine "Igor \\ Sikorsky Kyiv Polytechnic Institute", 35 Politekhnichna Str., 03056 Kyiv, Ukraine; yaryra1990@gmail.com \\ * Correspondence: hrubiak0andrii@gmail.com; Tel.: +380-68-0572-434
}

Citation: Moklyak, V.; Hrubiak, A.; Gogitidze, Z.; Yavorskyi, Y.

Biopolimer Peptide Batteries-A New Concept for Environmentally Friendly and Safer Energy Storage. Batteries 2021, 7, 50. https://doi.org/ $10.3390 /$ batteries7030050

Academic Editors: Carlos Ziebert and Pascal Venet

Received: 18 May 2021

Accepted: 13 July 2021

Published: 20 July 2021

Publisher's Note: MDPI stays neutral with regard to jurisdictional claims in published maps and institutional affiliations.

Copyright: (c) 2021 by the authors. Licensee MDPI, Basel, Switzerland. This article is an open access article distributed under the terms and conditions of the Creative Commons Attribution (CC BY) license (https:// creativecommons.org/licenses/by/ $4.0 /)$.
Abstract: The work shows a new approach to improving the performance of lithium power sources by using polypeptides as an active component of the cathode composition. Specifically, the experimental results of testing prototypes of lithium current sources with cathodes based on polypeptides, which demonstrate the value of the specific discharge capacity at the level of $2000-2700 \mathrm{mAh} / \mathrm{g}$, depending on the content of the organic component, are presented. The use of the intermittent galvanostatic titration mode during the discharge showed an increase in the specific indicators of the current sources in comparison with the continuous discharge at different specific load currents. Based on this, the effect of "relaxation recovery" of the cathode material based on polypeptides was discovered, the essence of which is a significant increase (recovery) of the open-circuit voltage when the load of the lithium current source is disconnected, which leads to an increase of the discharge capacity without external energy influences. The functionalization of the surface of thermally expanded graphite with polypeptide components made it possible to create a cathode material, the use of which in lithium current source models increased the specific discharge capacity to $19,000 \mathrm{~mA} \mathrm{~h} / \mathrm{g}$ at a discharge current of $10 \mathrm{~mA} / \mathrm{h}$.

Keywords: polypeptides; lithium current sources; cathode composition; biopolymer compounds; specific capacity; structure restoration

\section{Introduction}

One of the promising directions in terms of improving lithium power sources (LPS) is the use of organic components for the formation of cathode compositions [1]. Basically, they are used as a template matrix, on the basis of which $3 \mathrm{D}$ hierarchical structures are formed with subsequent removal or mineralization of the template (solving the problem of cathode aggregation and degradation) [2-6]. Another option for the use of organic components is the formation of amino acid conductivity bridges between the active component and the conductive agent (ensuring effective electron-ion transport) [7]. Additionally, as an option for improving the characteristics of LPS cathodes, they propose the synthesis of ordered 3D biopolymers with inclusions of an electrochemically active inorganic component [8].

In general, organic battery materials offer an interesting alternative to the already proven inorganic battery materials. Their main advantage is low energy consumption at the production stages, environmental friendliness, efficient utilization and recovery of lithium. At the same time, they do not undergo the structural transformation characteristic of crystalline materials, leading to the gradual destruction of materials during charge/discharge and allow bypassing the limitations of slow diffusion of a solid, which are often found in inorganic materials. Authors Bitenc et al. also note the special efficiency of organic 
cathodes based on molecular and polymeric compounds of quinones in the case of using polyvalent metal anodes [9-11].

The aim of this work is to study the electrochemical activity of biopolymer compounds of the protein series and to assess the capacity characteristics of the corresponding LPS, so-called "Biopolimer Peptide Batteries". Currently, only a few works in this direction are known, in particular in [8-13] pilot electrochemical studies of synthetic protein compounds as LPS cathodes were carried out. In [8], relatively low specific capacity values $<100 \mathrm{mAh} / \mathrm{g}$ in the range of $0-3 \mathrm{~V}$ were recorded for peptide nanofibers based on diphenyl-alanine. However, at the same time, it is stated in $[12,13]$ that a potential window is observed for an electrochemical system with electrodes made of composites of carbon black and synthetic polypeptides containing either viologen or 2,2,6,6-tetramethylpiperidine-1-oxyl (TEMPO) about $1.5 \mathrm{~V}$, which is suitable for low power systems such as biosensors. Thus, the question of the prospects and expediency of using this class of materials as LPS cathodes remains open.

In this work, we investigated the electrochemical properties of small-sized organic polypeptides $(<150 \mathrm{kDa})$ and composites based on them, and also estimated the specific capacity characteristics of the corresponding LPS. This kind of research has not been recorded before. We set the high electrochemical activity of exactly natural polypeptides, which have the ability to achieve high values of the discharge capacity of lithium current sources. Our investigation shows the opportunity to use the small-sized naturals polypeptides $(<150 \mathrm{kDa})$ in their testing as an active component of the cathode of lithium current sources. We identify the optimal conditions for the formation of cathodes, which will ensure the achievement of maximum discharge capacities. Due to the unique properties of natural polypeptides a demonstration of the phenomenon of relaxation recovery of the cathode material occurs, which provides a significant improvement in the discharge characteristics of the batteries. A separate point should be noted in research on the implementation of functionalization of carbon material by natural polypeptides, which leads to a significant increase in the specific discharge capacity of lithium batteries.

\section{Results}

\subsection{Electrochemical Activity}

The experimental profiles of the discharge curves of LPS with a cathode active organic component content of $X=20-77$ mass \% are shown in Figure 1a. They were obtained in a galvanostatic mode with a specific discharge current of $10 \mathrm{~mA} / \mathrm{g}$. The general view of the discharge curves has a classic S-shape for the used LPS mode with the formation of a potential plateau in the range of 2.5-1.8 V. An increase in the content of the organic component in the cathode mixture leads to an increase in the specific capacity of "Biopolimer Peptide Batteries" according to a close to linear law at a rate of $15 \mathrm{~mA} \mathrm{~h} /(\mathrm{g} \mathrm{wt} . \%)$ in terms of $1 \%$ biopolymer (Figure 1a, inset). At the same time, this leads to a decrease in the characteristic values of the discharge plateau potentials from 2.5 to $2.1 \mathrm{~V}$ for Bio20 cathodes and to 2.1-1.8 V for Bio77. It should be noted that the formation of additional small plateaus occurs at the beginning of the discharge in the case of Bio20 cathodes at $2.4 \mathrm{~V}$ and Bio40-2.15 V, which is associated with the high content of additional components in the cathode mixture and the corresponding kinetic processes. Thus, the optimal ratio of biopolymers/Super P/PVDF $=77 / 18 / 5$ has been established in terms of reaching the maximum specific capacity of $2750 \mathrm{~mA} \mathrm{~h} / \mathrm{g}$ in the range of $4.0-1.0 \mathrm{~V}$, and the values of the discharge potentials plateau at 2.1-1.8 $\mathrm{V}$ for Bio77 cathodes. 


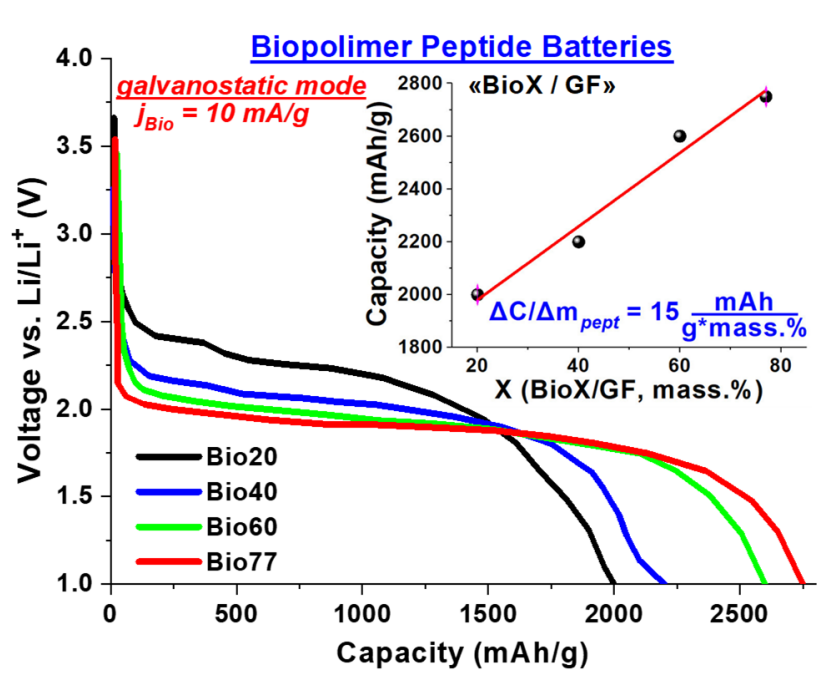

(a)

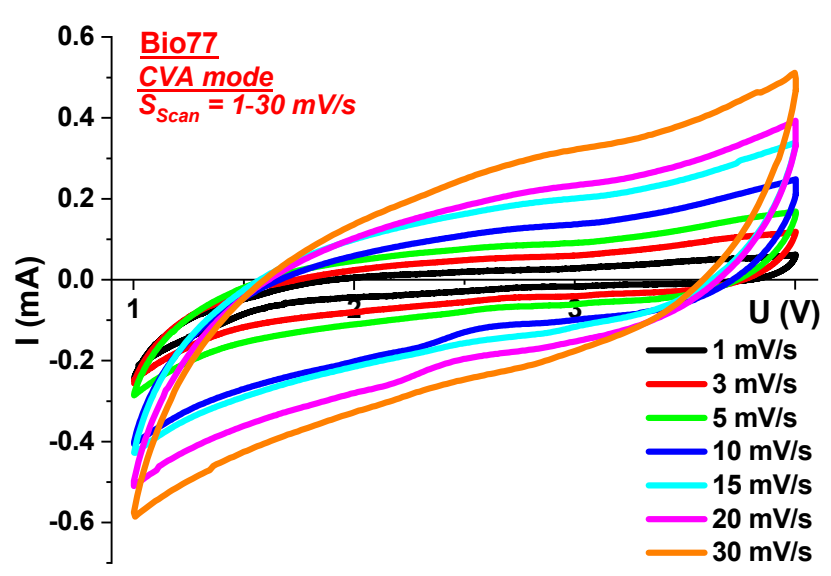

(c)

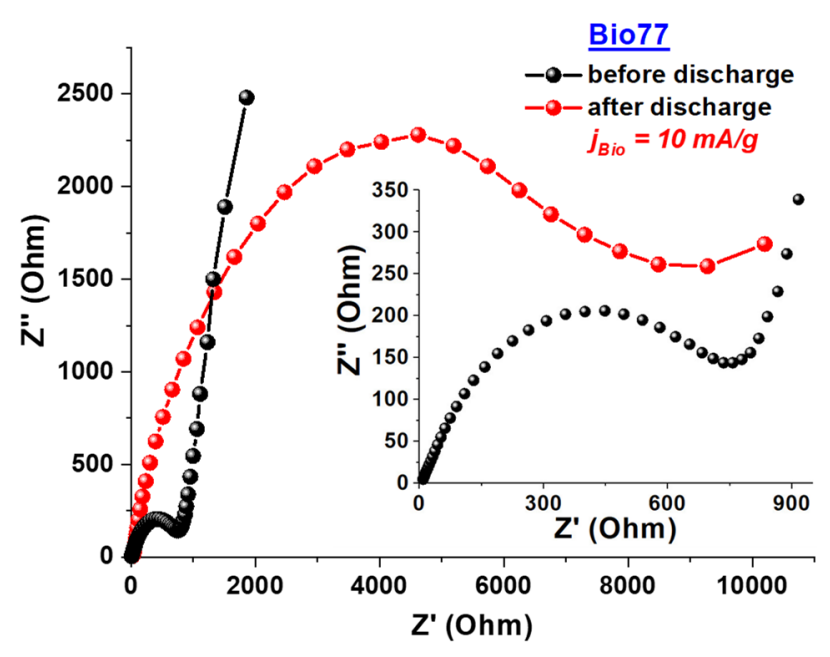

(b)

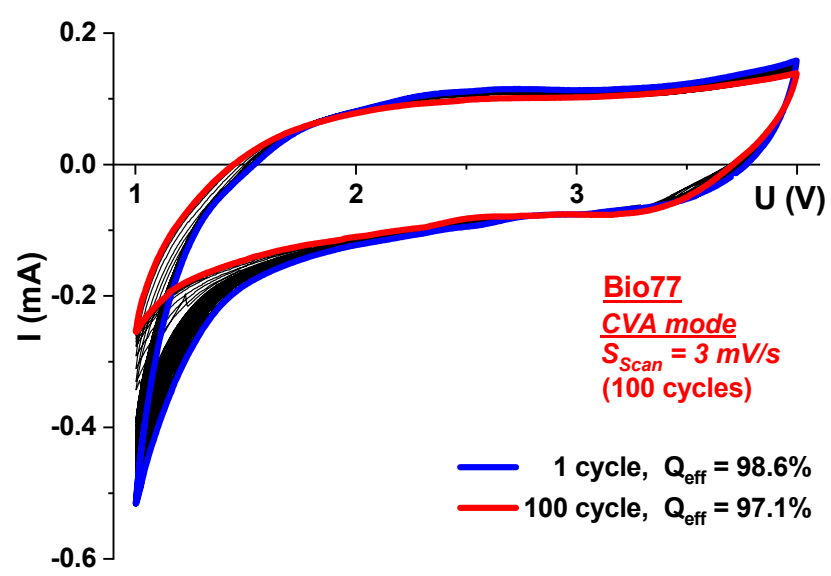

(d)

Figure 1. Electrochemical testing of "Biopolimer Peptide Batteries" with BioX cathodes:(a) discharge curves in galvanostatic mode for different organic component content $X=20-77 \mathrm{wt} \%$ (the inset shows the corresponding concentration dependence of the specific capacity of batteries); (b) Nyquist diagrams for the Bio77 case before and after discharge to $1.0 \mathrm{~V}$ at a current of $10 \mathrm{~mA} / \mathrm{g}$ (the high-frequency region is scaled in the inset); (c,d) CVA curves for the Bio77 case at different rates of potential change and a sweep over 100 cycles at a rate of $S_{\text {Scan }}=3 \mathrm{mV} / \mathrm{s}$, respectively.

We suggest that the high electrochemical activity of polypeptides is provided by several possible mechanisms of discharge reactions. First, there is the possible reaction of the addition of lithium-ion to the carboxyl group of the peptide unit. The course of such a reaction is the most possible given that the deprotonation of the carboxyl group or weakly bonded side $\mathrm{H}$ atoms occurs in the entire energy range, starting from $\approx 0 \mathrm{eV} \mathrm{[14].} \mathrm{We} \mathrm{be-}$ lieve that along with this, the mechanism of attachment of lithium ions to double-bonded oxygen on the side branches of peptide units is realized [15]. When lithium is attached to oxygen, the $\mathrm{C}=\mathrm{O}$ double bond is broken, and the $\mathrm{C}=\mathrm{N}$ double bond is formed with the release of the hydrogen ion, as in the case of the addition of lithium to the carboxyl group of the peptide unit. This mechanism of reactions does not contradict the above and allows to increase the load of lithium on the formula unit of the peptide unit. It is understood that in the case of natural polypeptides, there is significant molecular weight dispersion and various side radicals in the peptides, including aromatic rings and carboxyanhydride groups, which will also provide current-forming reactions by rearranging double bonds, deprotonation or even breaking the rings. However, the two reaction mechanisms presented are still the main ones and will be implemented in each peptide chain separately. 
In Figure $1 \mathrm{~b}$ shows typical Nyquist diagrams for layouts of LPS with Bio77 cathodes before and after discharge in galvanostatic mode with a specific discharge current of $10 \mathrm{~mA} / \mathrm{g}$, before discharge in the high-frequency region (Figure 1b, inset). In a given frequency range, the formation of a semicircle can be attributed to the interaction of $\mathrm{Li}^{+}$ions with the interface between the cathode/electrolyte material and its transfer through this surface, accompanied by hard mass transfer, which is overcome by diffusion-controlled processes. This type of interaction mechanism characterizes an electrochemical reaction because we transfer the charge of $\mathrm{Li}^{+}$ions across the interface cathode material/electrolyte [16]. A simulation of experimental impedance holographs indicates a sufficiently high resistance to charge transfer through the electric double layer at the electrode/electrolyte interface-about $1 \mathrm{k} \Omega$, which is controlled by diffusion mass transfer. The low-frequency section of the Nyquist diagram before the battery discharge has the shape of a quasi-vertical line, which indicates the predominance of the capacitive component in the overall system impedance. The recorded results are fully consistent with a sharp drop in the discharge potential from $4.0 \mathrm{~V}$ to $2.1 \mathrm{~V}$ at the initial stages of battery operation, which unambiguously indicates the processes of significant charge accumulation at the electrode/electrolyte interface and the formation of a corresponding capacitive electric double layer.

After the discharge of LPS (Bio77) on Nyquist diagrams, the diameter of the semicircle at high and medium frequencies increases significantly (Figure 1b), which corresponds to an increase in the charge transfer resistance at the electrode/electrolyte interface by almost an order of magnitude. This indicates the formation of a surface layer of $\mathrm{Li}^{+}$ions on the cathode surface, which prevents effective diffusional mass transfer. As a result of the discharge at the cathode/electrolyte interface, the concentration of lithium cations whose penetration into the cathode volume is limited by the mass transfer of the interface and the diffusion coefficient increases. The interaction of lithium ions with the interface and the presence of electrolyte anions can cause a number of undesirable surface reactions that will cause the formation of a passivating film on the cathode surface [17-19], which will complicate the further transport of lithium ions. The contribution of such a layer will be reflected in the impedance in the form of an increase in the semicircle responsible for the boundary resistance. Thus, it is the rate of diffusion processes of charge transfer at the electrode/electrolyte interface in this case that acts as the main limiting factor of current-forming reactions with an increase in specific discharge currents.

Cyclic voltammograms (CVA) for "Biopolimer Peptide Batteries" models with Bio77 cathodes in the voltage range of 1.0-4.0 V indicate the absence of pronounced electrochemical redox reactions (Figure 1c,d). Insignificant broadened redox peaks were recorded for scanning rates $S_{\text {Scan }}=10-20 \mathrm{mV} / \mathrm{s}$ in the vicinity of $2.2-2.3 \mathrm{~V}$ on the cathode branch (Figure 1c). At lower scanning speeds, the shape of the CVA curve has a shape close to rectangular with preservation of insignificant asymmetry about the abscissa axis and reaching the saturation current when the final potentials are reached. In this case, a horizontal plateau is formed on the anode branch at $0.05 \mathrm{~mA}$. Thus, the results obtained indicate mainly the capacitive type of charge accumulation at this stage and are fully consistent with the conclusions of impedance spectroscopy. In the case of higher scanning speeds $S_{\text {Scan }}=10-30 \mathrm{mV} / \mathrm{s}$, only insignificant local inflections of the CVA curves are observed (Figure 1c). This indicates the presence of a continuous distribution in a wide range of the characteristic redox potential of the corresponding electrochemical reactions involving low molecular weight polypeptides, which is due to the variety of guest positions for lithium ions in their structure and the variable composition of the radicals of the main peptide chain. In this case, the highly developed side surface of the biopolymer will ensure both the occurrence of redox reactions and effective surface adsorption of lithium ions, and the stability of the amide bond of the main amino acid chain ensures long-term preservation of operational characteristics. Figure 1d shows the results of CVA testing of LPS mock-ups with Bio77 cathodes for 100 cycles at a rate of $S_{\text {scan }}=3 \mathrm{mV} / \mathrm{s}$. The Coulomb efficiency of an electrochemical cell in the CVA cycling mode was $98.6 \%$ at one cycle and $97.1 \%$ at 100 cycles, which indicates a capacitive degradation of no more than $2 \%$. 


\subsection{Relaxation Recovery}

The next stage of the study was to obtain bit profiles of lithium power source prototypes with the cathode Bio77 in the mode by the Galvanostatic Intermittent Titration Technique method (GITT). This case presents a comparison of discharge profiles of models of lithium power sources with cathodes based on polypeptides in the case of continuous discharge and in the mode of intermittent titration at the same load currents.

Figure 2a,b shows the results of testing the layouts of "Biopolimer Peptide Batteries" with Bio77 cathodes GITT with discharge current densities of 10 and $30 \mathrm{~mA} / \mathrm{g}$ in the mode at which the "discharge time/relaxation" ratio is 5 . In this case, the relaxation time for different current densities was $5 \mathrm{~h}$ and $1 \mathrm{~h}$, respectively. In the mode of GITT, the horizontal plateau of the discharge is formed at approximately the same potential values as in the case of a continuous discharge. However, the value of the horizontal plateau in the titration mode is much larger, which we associate with the effect of relaxation reduction of the cathode material. As can be seen from Figure 2a, there is an abnormal double increase in the specific capacity of the batteries up to $4900 \mathrm{mAh} / \mathrm{g}$ in the range of $4.0-1.0 \mathrm{~V}$ compared to continuous discharge. It was found that the degree of increase in the "relaxed" capacity directly depends on the relaxation time for the selected discharge current density (Figure 2b).

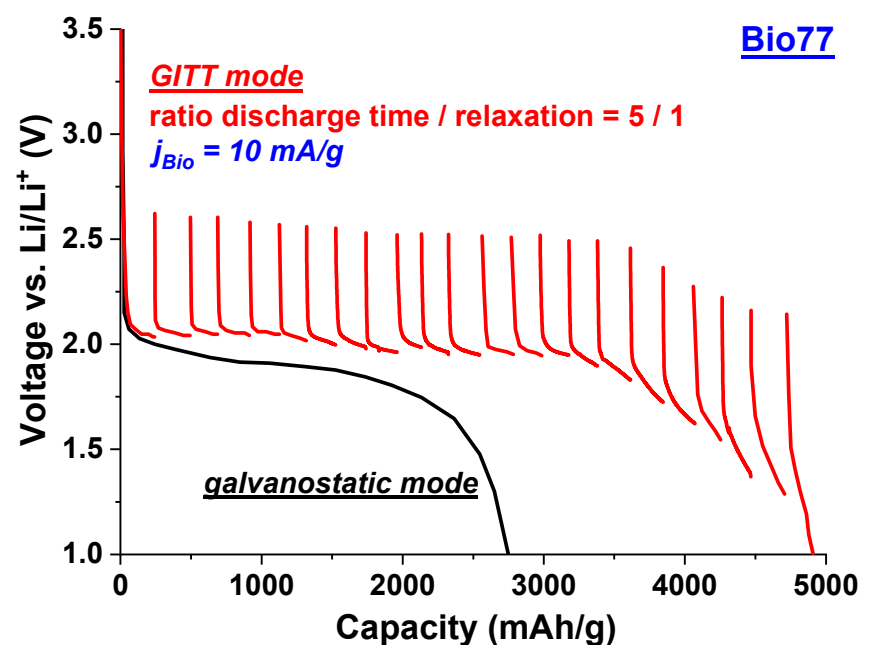

(a)

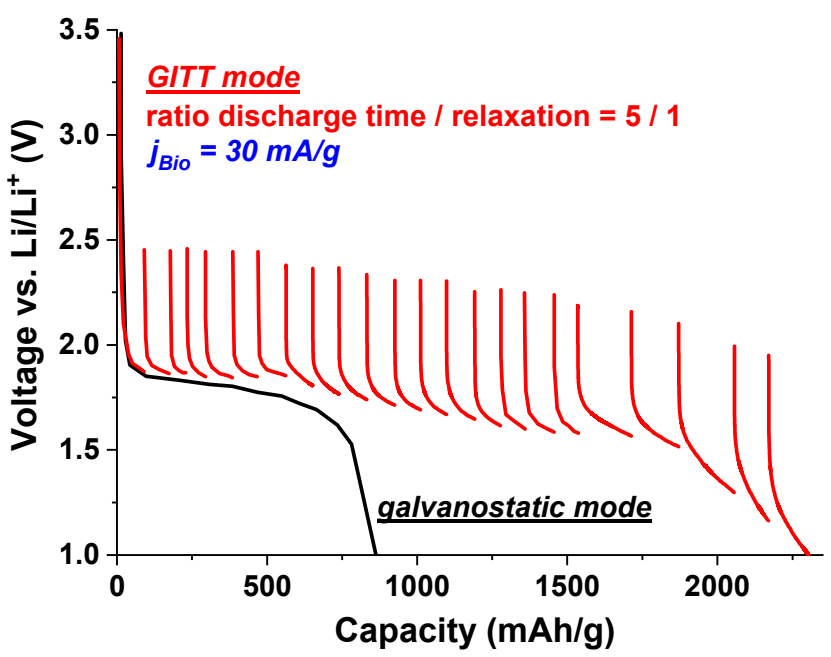

(b)

Figure 2. Discharge curves of "Biopolimer Peptide Batteries" (Bio77) obtained in the mode of galvanostatic intermittent titration with discharge current densities of $10(\mathbf{a})$ and $30(\mathbf{b}) \mathrm{mA} / \mathrm{g}$.

\subsection{Surface Functionalization}

Figure 3a,b shows the results of electrochemical studies of BioP/TEG composite cathodes. The basis of the composite is TEG with a highly developed specific surface, which was subsequently functionalized directly in the mother liquor of active low molecular weight polypeptides by their deposition on the reaction surface of carbon. In this case, the functionalization of the surface implies multiple increases in the trapping centers of lithium ions during the course of electrochemical reactions due to the attraction of various radicals of the polypeptide chain attached to the carbon surface to the current-forming process. The obtained experimental discharge curves of LPS with BioP/TEG cathodes (Figure 3a) demonstrate the specific discharge capacity at the level of $19,000 \mathrm{mAh} / \mathrm{g}$ in the range of $4.0-1.0 \mathrm{~V}$ for a current density of $10 \mathrm{~mA} / \mathrm{g}$, which is almost an order of magnitude higher than similar discharge indices for Bio77 cathodes. As in the previous cases, the discharge curve has a classic S-shaped form with the formation of a horizontal plateau at the level of 2.0-1.9 V and subsequent partial subsidence and stabilization at $1.78-1.75 \mathrm{~V}$. However, an increase in the discharge current density to $20 \mathrm{~mA} / \mathrm{g}$ leads to a 
sharp decrease in the specific discharge capacity to $7900 \mathrm{mAh} / \mathrm{g}$. A further increase in the discharge current density causes a decrease in the value of the specific discharge capacity according to the exponential law with saturation reaching $1500 \mathrm{~mA} \mathrm{~h} / \mathrm{g}$ at a current density of $100 \mathrm{~mA} / \mathrm{g}$ (Figure 3a, inset). Cyclic voltammograms for "Biopolimer Peptide Batteries" models with BioP/TEG cathodes in the voltage range of 1.0-4.0 V, similarly to the Bio77 cathodes, also indicate the absence of pronounced electrochemical redox reactions (Figure 3b). A distinctive feature, in this case, is the relatively large values of currents (almost three times) for the corresponding scanning rates, which confirms the recorded large values of the specific capacity of electrochemical cells. At low scanning speeds, the CVA curve, as in the case of Bio77, has a shape close to rectangular with an output to the saturation current at the anode branch in the vicinity of $0.2 \mathrm{~mA}$, which indicates the predominance of the capacitive type of charge accumulation at this stage. According to the results of CVA testing of BioP/TEG cathodes for 100 cycles at a rate of $S_{\text {Scan }}=3 \mathrm{mV} / \mathrm{s}$, the Coulomb efficiency of the corresponding electrochemical cells was $88.4 \%$ per 100 cycles (Figure 3b, inset).

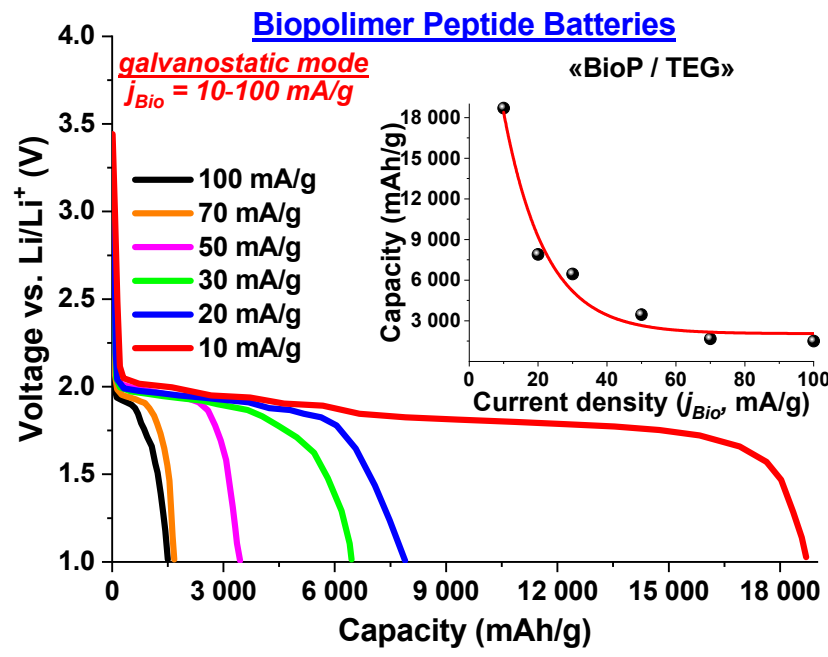

(a)

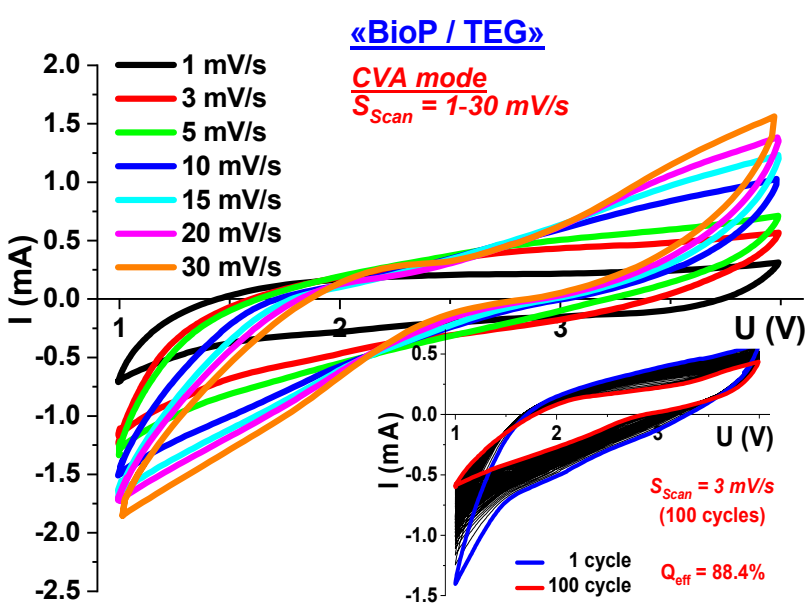

(b)

Figure 3. Electrochemical testing of "Biopolimer Peptide Batteries" with BioP/TEG composite cathodes: (a) discharge curves in galvanostatic mode for various discharge current densities of 10-100 mA/g (the inset shows the corresponding dependence of the specific battery capacity on the current density); (b) CVA curves for rates of potential change of 1-30 mV/s (in the inset, a sweep over 100 cycles at $\mathrm{S}_{\mathrm{Scan}}=3 \mathrm{mV} / \mathrm{s}$ ).

\section{Discussion}

\subsection{Electrochemical Activity}

An analysis of the experimental discharge curves shows that LPS models with cathodes based on polypeptides demonstrate good capacitive performance-the obtained values of the specific discharge capacity significantly exceed those of all available types of cathodes, both theoretical and experimental [20]. At the same time, the fixed capacitive indicators are stable and reproducible.

As can be seen, the content of the active polypeptide component in the cathode composition determines the final specific discharge capacity of the model of an LPS based on it. A clear positive correlation between the relative content of polypeptides and capacitive parameters made it possible to select the optimal composition of the cathode composition, for which the maximum specific capacity parameters of the discharge of the LPS were achieved. We see that the increase in the content of the active component leads to a decrease in the potential at which the plateau of the discharge profile is formed and the total discharge capacity increases. Additionally, for curves of the prototype of batteries in which there is a less active component, there is a noticeablly faster decrease in potential over time. 
We explain this result by the fact that in the case of using lower relative concentrations of biopolymers (i.e., Bio20 and 40) in the cathode mixture, there is better dispersion of the active material. In other words, the biopolymer chains or any aggregate complexes formed by them-in the case of cathode mixtures with low concentrations-will be destroyed, and the dispersion of the distribution of the active component in the cathode mixture increases. The process of depolymerization of the active material is not excluded. This in turn, leads to an increase in the area of the interfacial surface and a decrease in the free path length of the charge in the active material. In addition, as the size of biopolymers decreases and the value of their dispersed distribution increases, the value of the surface energy of the particles increases. The number of active centers that can participate in current-forming reactions is also growing. These mechanisms lead to an increase in the reaction rate-the number of reactions per unit time-which causes an increase in the potential on the galvanostatic curve. Similar processes occur in [18], where for an inorganic material with smaller particles, the discharge curve is formed at relatively higher potentials and the efficiency of reactions increases. On the other hand, there is an additional increase in surface energy due to the addition of lithium ions to the structure, which in turn leads to a decrease in the energy difference before and after the introduction of lithium [21]. Thus, during the discharge of the current source in the case of more dispersed cathode systems, the potential plateau of the discharge curve decreases faster, although it is formed at relatively higher potentials.

The work of the LPS model with a biopolymer-based cathode opens a new concept of lithium batteries, which can be called "Biopolimer Peptide Batteries". The mechanisms of stream-forming processes in such a battery are associated with structural and electrochemical features and advantages that biopolymer compounds have in comparison with inorganic materials [22]. In particular, the biocompatibility and stability of polypeptides with inorganic components during the discharge process makes it possible to implement a number of mechanisms of electrochemical transformations with the participation of a highly developed lateral surface of the biopolymer chain through electrochemical reactions and surface adsorption/desorption of cations.

The results of impedance studies, which demonstrate a significant difference in charge transfer through the cathode surface after the discharge, serve as a confirmation of the implementation of the mechanism of initialization of the self-assembly processes of biopolymers during the discharge of LPS. The reason for this may be due to the formation of a surface layer during a discharge on the surface of the cathode, which prevents diffusion processes and functions as a barrier for the interphase transfer of electrons. In addition, there is a possibility in the course of the LPS discharge, the processes of "re-polymerization" of individual polymer chains are initiated [23]. As a result, the length of the biopolymer chains increases, and a neutral charge is formed on the cathode surface. The formation of long polymer chains, the growth of the surface-modified layer and the restructuring of the cathode material/electrolyte interface surface cause the formation of a barrier layer with high electrical resistance. It is this process that is reflected on the LPS model hodograph after discharge to $1.0 \mathrm{~V}$.

On the other hand, the formation of conduction bridges between the active organic component and carbon materials in cathode systems will provide effective electron-ion transport and the course of rapid reactions [24]. Thus, due to the use of polypeptide compounds, problems with unsatisfactory electron-ion transport and structural transformations of cathode compositions during the operation of prototypes of current sources are solved. As a result, "Biopolimer Peptide Batteries" have been obtained, the energy capacity indicators of the discharge of which surpass the known analogs. In addition, the values of the specific discharge currents at which the discharge occurs were chosen as the most typical for LPS at rated recommended loads, regardless of the size or class of the current source [20]. This testifies to the prospects of building high-capacity lithium batteries with cathodes based on polypeptide compounds and the formation of the so-called "Biopolimer Peptide Batteries" as a new concept of LPS. 
At the same time, in interpreting the studies carried out with respect to cyclic voltamerograms, it can be noted that the mechanisms of electrochemical activity of polypeptides during the discharge of LPS based on them are not the cause of irreversible degradation. The reversibility of CVA curves at high scan rates and their symmetry indicates that the degradation of the cathode material does not occur. Additionally, the presence of CVA curves at lower scanning speeds of areas of current independence from potential, which is characteristic of capacitive charge accumulation due to the formation of a double electric layer and broadening of redox maxima, which suggests a parallel course of various mechanisms of current-forming processes during of LPS discharge. Thus, in LPS with cathodes based on polypeptides, the mechanisms of pseudocapacitive charge and Faraday types of charge accumulation are implemented, which leads to a significant increase in specific capacitive characteristics and also ensures the effective preservation of its voltage for a long time of operation.

\subsection{Relaxation Recovery}

During intermittent galvanostatic titration of GITT, an increase in the final specific discharge capacity up to $1.0 \mathrm{~V}$ compared to continuous discharge was recorded. In the case of intermittent galvanostatic titration with a specific current of $10 \mathrm{~mA} / \mathrm{g}$, as in the case of a continuous discharge, a sharp drop in potential occurs to voltage values of $2.0-2.1 \mathrm{~V}$, at which a horizontal plateau is formed. In the process of "relaxation" for 5 hours, the open-circuit voltage increases by $0.5-0.8 \mathrm{~V}$. The next stage of the discharge is characterized by the continuation of the discharge curve after the corresponding voltage reaches $2.0-2.1 \mathrm{~V}$. It was also recorded that with an increase in the specific current, the potential decreases, at which the plateau of the discharge curve is stabilized. In the case of galvanostatic titration with a current of $30 \mathrm{~mA} / \mathrm{g}$, a significant increase in the capacitive characteristics of the discharge is also observed in comparison with the case of a continuous discharge. The increase in the specific capacity of the discharge is observed with galvanostatic titration of GITT and the formation of a horizontal plateau during the discharge is 1.7-1.8 V. At the initial stages of the discharge, the course of the galvanostatic curves was identical, and at a potential of about $1.7 \mathrm{~V}$, a smoother drop in the potential for the curve is observed obtained in titration mode.

Based on these experiments, it was proposed to call the feature whereby "Biopolimer Peptide Batteries" models increase the maximum value during intermittent galvanostatic titration the effect of "relaxation recovery" of the cathode material, since this behavior was observed only in cases of using polypeptide compounds as an active cathode composition. The essence of the effect is a significant increase (recovery) of the open-circuit voltage in the order of $0.5-0.8 \mathrm{~V}$ when the load is disconnected. Continuation of the discharge profile after switching on the load ensures that the operating voltage is maintained, at which a plateau is formed. Therefore, each stage of discharge after relaxation can be considered as a discharge cycle, similar to the cycle of operation of a lithium-ion battery. At the same time, in a lithium-ion battery, in order to restore its open-circuit voltage and the ability to work in the future, one needs to charge the battery, that is, provide an external charge, then in the case of "Biopolimer Peptide Batteries", it is enough to turn it off for a while to the voltage has resumed. One cycle of "relaxation" in the case of a discharge with a specific current of $10 \mathrm{~mA} / \mathrm{h}$ accumulates a specific discharge capacity of $200 \mathrm{~mA} \mathrm{~h} / \mathrm{g}$, which is comparable to the specific capacitances of commercial analogs cathodes. Realizing this analogy, we see that in the case of "Biopolimer Peptide Batteries" operation in the "relaxation" recovery mode, it is possible to obtain a discharge capacity proportional to 23 discharge cycles of a lithium-ion battery with no external energy consumption. When the "Biopolimer Peptide Batteries" model is discharged with a specific current of $30 \mathrm{~mA} / \mathrm{g}$, we observe lower values of the specific discharge capacities. However, here, too, there is a tendency to an increase in the specific capacity of batteries in the "relaxation" mode in comparison with a continuous discharge. 
To understand the mechanism of the relaxation recovery effect, we need to consider the process of voltage increase when the load current is disconnected. Relaxation of opencircuit voltage recovery of lithium and lithium-ion batteries is a characteristic phenomenon observed when the load current is disconnected from the source and is mainly due to two processes: equalization of charge concentration from the cathode material/electrolyte interface and equalization of a carrier concentration of charge, again on the interface of the cathode material/electrolyte in the volume. These two processes are associated with the formation of the charge transfer overpotential $\eta \mathrm{CT}$ and the overpotential of mass transfer ๆMT [25], which cause an increase in the open-circuit voltage when the load current is unlocked. Additionally, if the overpotential of the charge is restored instantly and is limited mainly by the conductivity of the material, the overpotential of mass transfer is restored much more slowly. For inorganic cathode materials of lithium-ion batteries, in the current-generating mechanisms that are associated with lithium intercalation reactions in the cathode structure cavities, the limiting factor for the mass transfer of charge carriers is mainly the diffusion coefficient of lithium. That is why the process of voltage recovery lasts for a long time, and its value reaches saturation after equalization of concentrations [26]. For peptide cathode materials, the process of restoring the potential when the load current is disconnected has a slightly different character and generally consists of the involvement in current-forming processes of all active centers of the cathode mixture. As there are different locations for peptides in the capture of lithium ions, several parallel reactions associated with polymerization, regrouping of double bonds in the peptide chain and current-forming processes involving aromatic and other carboxyl groups are possible. Relaxation ensures the phasing of each reaction over the entire volume of the cathode material and the involvement of all active centers of current formation. In other words, this type of process that occurs during relaxation, in our case with the participation of peptides, is called self-organization of the system or the process of self-ordering inherent in organic components [24]. It is logical that the relaxation of our battery allows us to achieve higher discharge capacity because more active current-forming centers are involved and there is no rapid formation of a passive surface film, which prevents further interaction of lithium ions with the cathode material.

The discharge capacity is achieved without external charge consumption, which is a significant advantage of such current sources. Until now, no analogs of this behavior of a battery with an inorganic cathode in the galvanostatic titration mode have been found. The effect of relaxation reduction of the cathode material has been recorded and may be interesting for the construction of prototypes of high-power self-healing electrochemical power sources. The peculiarity of this effect is the absence of any external influences or the consumption of excess energy to achieve the highest capacitive performance. It is enough to provide only the conditions for relaxation of a battery with a cathode based on biomaterial, and due to this, its specific discharge capacity can be increased. The fixed effect can be associated with the mechanism of restoration of the structure of the active component after the removal of the LPS load. The operational parameters of power sources based on such principles of recovery work can significantly exceed the corresponding characteristics of traditional power sources.

\subsection{Surface Functionalization}

In addition, interesting in terms of the development of new polyfunctional materials is the ability to modify the surface of materials using biopolymers. In this case, due to the deposition of polypeptides on the surface of the carbon material, the functionalization of the structure takes place, which consists in the formation of biopolymer organic functional groups on the surface of inorganic compounds in the form of electrochemically active centers or bonds. As we have shown, composites of this kind exhibit a significant synergistic effect, which results in an increase in the capacitive parameters of the LPS discharge. The functionalization of the surface made it possible to significantly increase the specific discharge capacity of LPS based on polypeptides. In addition, high values of specific 
discharge capacities have been achieved in the case of a tenfold increase in the load current in the galvanostatic mode.

\section{Materials and Methods}

Electrochemical studies of "Biopolimer Peptide Batteries" were carried out using the methods of galvanic and potentiometry (charge/discharge system TIONiT P2.00-xx), as well as impedance spectroscopy (impedance spectrometer AUTOLAB PGSTAT12, FRA2 module, frequency range from $10^{-2}$ to $10^{5} \mathrm{~Hz}$ ).

Cathode materials were prepared by homogenizing a mixture of an organic component (small-sized polypeptides ( $<150 \mathrm{kDa}$ ) of plant origin stabilized with $\mathrm{NaCl}$ and $\mathrm{K}_{2} \mathrm{HPO}_{4}$ salts), a conductive additive (Super $\mathrm{P}$ ) and a PVDF binder solution ( $\mathrm{N}$-methylpyrrolidone) in a mass ratio (20-77): (75-18): 5 . The resulting cathode mixture was applied to a current collector made of commercial graphite foil (GF, Yichang Xincheng Graphite Co., Ltd., Yichang, China), followed by drying in vacuum (60-100 C) and pressing at a pressure of 5 tons $/ \mathrm{cm}^{2}$.

In order to establish the effect of the amount of active ingredient on the discharge characteristics, we made several different cathode mixtures in which the ratio of active ingredient to other components was 20, 40, 60 and $77 \%$. On the basis of these mixtures, models of lithium current sources were formed and their discharge characteristics were investigated. Marking models of lithium power sources relative to the cathode was as follows-BioX, where $X=20-77$ wt. $\%$ - organic content. Subsequently, based on the obtained results, the best cathode mixture was determined and it was used for further studies, in particular, for galvanostatic titration.

Another approach to the preparation of cathodes was to functionalize the carbon surface with active centers. The logic of these studies was to create on the surface of the cathode, which was a plate of thermally expanded graphite (TEG-thermally expanded graphite), a large number of electrochemically active polypeptide centers. This type of composite system should improve the flow of reactions that occur during discharge. The formation of composite cathodes of the BioP/TEG type was carried out by the method of direct deposition of small-size polypeptides (BioP) on a TEG substrate from a corresponding stock protein solution $(0.9 \% \mathrm{NaCl}$ in $0.004 \mathrm{M}$ potassium phosphate buffer), similarly to the developed technique $[27,28]$. Subsequently, the gel is polymerized by evaporation of the solution at a temperature of $50-60{ }^{\circ} \mathrm{C}$ until a polypeptide film is formed on the surface of the TEG substrate.

Standard tests of "Biopolimer Peptide Batteries" in galvanostatic mode were carried out in laboratory prototypes of the Swagelok type CR2032 format in the potential range from 1.0 to $4.0 \mathrm{~V}$ relative to $\mathrm{Li} / \mathrm{Li}^{+}$with current densities of $10-100 \mathrm{~mA} / \mathrm{g}$ (in terms of the mass of active organic components). Li-foil $(500 \mu \mathrm{m})$ and $1 \mathrm{M} \mathrm{LiBF}_{4}$ solution in gammabutyrolactone were used as anode and electrolyte, respectively. Investigations of the Coulomb efficiency of LPS by the method of cyclic voltammetry were carried out in the range of potential sweep rates $\Delta \mathrm{V} / \Delta \mathrm{t}=1-30 \mathrm{mV} / \mathrm{s}$. The calculation of the specific capacity indicators of LPS was carried out relative to the mass of the active organic component $m_{\text {pept }}$ according to the formula: $C_{B i o X}=I \cdot t / m_{\text {pept }}$, I-constant discharge current, $\mathrm{t}$-discharge time.

\section{Conclusions}

We present a new approach to the concept of "organic batteries", which consists of using the electrochemical activity of the natural, small-sized $(<150 \mathrm{kDa})$ polypeptides as the active cathode component of lithium power sources. It was found that the formed "Biopolimer Peptide Batteries" possess high specific capacitive indicators reaching $2700 \mathrm{mAh} / \mathrm{g}$ at a discharge up to $1.0 \mathrm{~V}$ with a specific current of $10 \mathrm{~mA} / \mathrm{h}$. We established that the increase in the content of the active component leads to stabilizing the plateau of the discharge profile that is formed and the total discharge capacity increases.

The effect of "relaxation recovery" of the cathode material was discovered during intermittent galvanostatic titration of GITT on the "Biopolimer Peptide Batteries", with 
polypeptide-based cathodes. The effect of "relaxation recovery" is a significant increase in the open-circuit voltage when the load is disconnected, which leads to an increase in energy-intensive discharge indicators without external power-carrying actions. Due to this, the double increase in the specific capacity of batteries up to $4900 \mathrm{mAh} / \mathrm{g}$ in the range of 4.0-1.0 V has been achieved during operation in the "relaxation" mode in comparison with continuous discharge. At the same time, high capacitive discharge indicators are achieved without any external influences or excessive energy consumption.

The functionalization of the surface of thermally expanded graphite by low molecular weight polypeptides by their deposition on the reaction surface of carbon causes the multiple increases in the trapping centers of lithium ions occurs due to the attraction of various polypeptide radicals into the current-forming process. The obtained experimental discharge of "Biopolimer Peptide Batteries" with functionalized cathodes demonstrate a specific discharge capacity of $19,000 \mathrm{mAh} / \mathrm{g}$ in the range of 4.0-1.0 V for a current density of $10 \mathrm{~mA} / \mathrm{h}$.

Author Contributions: Conceptualization, V.M., A.H. and Z.G.; Software, V.M.; Data Curation, V.M.; Writing V.M. and A.H.; Term, A.H.; Methodology, A.H.; Validation, A.H.; Investigation, A.H. and V.M.; Visualization A.H.; Resources, Z.G.; Supervision, A.H. and Z.G.; Funding Acquisition Z.G.; Formal Analysis, V.M. and Y.Y.; Project Administration V.M. and Y.Y. All authors have read and agreed to the published version of the manuscript.

Funding: This research received no external funding.

Institutional Review Board Statement: Not applicable.

Informed Consent Statement: Not applicable.

Data Availability Statement: Not applicable.

Conflicts of Interest: The authors declare no conflict of interest.

\section{References}

1. Pirnat, K.; Bitenc, J.; Vizintin, A.; Krajnc, A.; Tchernychova, E. Indirect Synthesis Route toward Cross-Coupled Polymers for High Voltage Organic Positive Electrodes. Chem. Mater. 2018, 30, 5726-5732. [CrossRef]

2. Rosenman, G.; Beker, P.; Koren, I.; Yevnin, M.; Bank-Srour, B.; Mishina, E.; Semin, S. Bioinspired peptide nanotubes: Deposition technology, basic physics and nanotechnology applications. J. Pept. Sci. 2010, 17, 75-87. [CrossRef] [PubMed]

3. Nam, K.T.; Kim, D.-W.; Yoo, P.J.; Chiang, C.-Y.; Meethong, N.; Hammond, P.T.; Chiang, Y.-M.; Belcher, A.M. Virus-Enabled Synthesis and Assembly of Nanowires for Lithium Ion Battery Electrodes. Science 2006, 312, 885-888. [CrossRef]

4. Ryu, J.; Kim, S.-W.; Kang, K.; Park, C.B. Mineralization of Self-assembled Peptide Nanofibers for Rechargeable Lithium Ion Batteries. Adv. Mater. 2010, 22, 5537-5541. [CrossRef]

5. Kotsyubynsky, V.; Ostafiychuk, B.; Moklyak, V.; Hrubiak, A. Synthesis, Characterization and Electrochemical Properties of Mesoporous Maghemite $\gamma$-Fe2O3. Solid State Phenom. 2015, 230, 120-126. [CrossRef]

6. Ostafiychuk, B.K.; Kaykan, L.S.; Kaykan, J.S.; Deputat, B.Y.; Shevchuk, O.V. Composition, Microstructure, and Electrical Properties Control of the Powders Synthesized by Sol-Gel Auto-Combustion Method Using Citric Acid as the Fuel. Nanoscale Res. Lett. 2017, 12, 237. [CrossRef]

7. Jung, L.Y.; Belcher, A.M. Nanostructure design of amorphous FePO4 facilitated by a virus for $3 \mathrm{~V}$ lithium ion battery cathodes. J. Mater. Chem. 2011, 21, 1033-1039.

8. Ryu, J.; Kim, S.-W.; Kang, K.; Park, C.B. Synthesis of Diphenylalanine/Cobalt Oxide Hybrid Nanowires and Their Application to Energy Storage. ACS Nano 2009, 4, 159-164. [CrossRef]

9. Bitenc, J.; Pirnat, K.; Mali, G.; Novosel, B.; Vitanova, A.R.; Dominko, R. Poly(hydroquinoyl-benzoquinonyl sulfide) as an active material in Mg and Li organic batteries. Electrochem. Commun. 2016, 69, 1-5. [CrossRef]

10. Bitenc, J.; Pirnat, K.; Žagar, E.; Randon-Vitanova, A.; Dominko, R. Effect of salts on the electrochemical performance of Mg metal-organic battery. J. Power Sources 2019, 430, 90-94. [CrossRef]

11. Bitenc, J.; Vizintin, A.; Grdadolnik, J.; Dominko, R. Tracking electrochemical reactions inside organic electrodes by operando IR spectroscopy. Energy Storage Mater. 2019, 21, 347-353. [CrossRef]

12. Morris, M.A.; An, H.; Lutkenhaus, J.L.; Epps, T.H., III. Harnessing the power of plastics: Nanostructured polymer systems in lithium-ion batteries. ACS Energy Lett. 2017, 2, 1919-1936. [CrossRef]

13. Wang, S.; Park, A.M.G.; Flouda, P.; Easley, A.D.; Li, F.; Ma, T.; Fuchs, G.D.; Lutkenhaus, J.L. Solution-Processable Thermally Crosslinked Organic Radical Polymer Battery Cathodes. ChemSusChem 2020, 13, 2371-2378. [CrossRef] 
14. Muftakhov, M.V.; Shchukin, P.V. Destruction of Peptides and Nucleosides in Reactions with Low-Energy Electrons. Tech. Phys. 2018, 63, 747-758. [CrossRef]

15. Seebach, D. Structure and Reactivity of Lithium Enolates. From Pinacolone to Selective C-Alkylations of Peptides. Difficulties and Opportunities Afforded by Complex Structures. Angew. Chem. Int. Ed. Engl. 1988, 27, 1624-1654. [CrossRef]

16. Zhang, S.; Xu, K.; Jow, T. EIS study on the formation of solid electrolyte interface in Li-ion battery. Electrochim. Acta 2006, 51, 1636-1640. [CrossRef]

17. Rivard, S.; Young, B.; Heskett, D.; Dong, Y.; Hu, Y.; Lucht, B. Novel borate additives for lithium-ion battery cathode passivation investigated with hard x-ray photoelectron spectroscopy. APS March Meet. Abstr. 2017, L38, 003.

18. Chowdhury, R.; Banerjee, A.; Zhao, Y.; Liu, X.; Brandon, N. Simulation of bi-layer cathode materials with experimentally validated parameters to improve ion diffusion and discharge capacity. Sustain. Energy Fuels 2021, 5, 1103-1119. [CrossRef]

19. Zou, L.; He, Y.; Liu, Z.; Jia, H.; Zhu, J.; Zheng, J.; Wang, G.; Li, X.; Xiao, J.; Liu, J.; et al. Unlocking the passivation nature of the cathode-air interfacial reactions in lithium ion batteries. Nat. Commun. 2020, 11, 3204. [CrossRef]

20. Nitta, N.; Wu, F.; Lee, J.T.; Yushin, G. Li-ion battery materials: Present and future. Mater. Today 2015, 18, 252-264. [CrossRef]

21. Liu, C.; Neale, Z.G.; Cao, G. Understanding electrochemical potentials of cathode materials in rechargeable batteries. Mater. Today 2016, 19, 109-123. [CrossRef]

22. Bhattacharya, P.; Du, D.; Lin, Y. Bioinspired nanoscale materials for biomedical and energy applications. J. R. Soc. Interface 2014, 11, 20131067. [CrossRef] [PubMed]

23. Tlili, C.; Sokullu, E.; Safavieh, M.; Tolba, M.; Ahmed, P.M.U.; Zourob, M. Bacteria Screening, Viability, And Confirmation Assays Using Bacteriophage-Impedimetric/Loop-Mediated Isothermal Amplification Dual-Response Biosensors. Anal. Chem. 2013, 85, 4893-4901. [CrossRef] [PubMed]

24. Hu, K.; Jiang, Y.; Xiong, W.; Li, H.; Zhang, P.; Yin, F.; Zhang, Q.; Geng, H.; Jiang, F.; Li, Z.; et al. Tuning peptide self-assembly by an in-tether chiral center. Sci. Adv. 2018, 4, eaar5907. [CrossRef] [PubMed]

25. Brady, N.W.; Zhang, Q.; Knehr, K.W.; Liu, P.; Marschilok, A.C.; Takeuchi, K.J.; Takeuchi, E.S.; West, A.C. Discharge, Relaxation, and Charge Model for the Lithium Trivanadate Electrode: Reactions, Phase Change, and Transport. J. Electrochem. Soc. 2016, 163, A2890-A2898. [CrossRef]

26. Li, A.; Pelissier, S.; Venet, P.; Gyan, P. Fast Characterization Method for Modeling Battery Relaxation Voltage. Batteries 2016,2 , 7. [CrossRef]

27. Zurab Gogitidze. Information Carrier. Patent UA 85375, 11 November 2013.

28. Zurab Gogitidze. A Cathode Material. International Patent Application No. PCT/UA2020/000074, 31 July 2020. 